\title{
Cytokine-adsorbing hemofilter: old but new modality for septic acute kidney injury
}

\author{
Noriyuki Hattori ${ }^{*}$ and Shigeto Oda
}

\begin{abstract}
While evidence supporting the hypothesis that blood purification improve outcome in septic acute kidney injury (AKI) has not been established, many physicians hope to improve outcome in septic AKI by blood purification. Elucidation of the pathophysiology of sepsis has revealed close involvement of humoral mediators, including cytokines, pathogen-associated molecular patterns, and alarmins, in the development of severe sepsis. Removal of substances by blood purification involves three major principles, namely filtration, dialysis (diffusion), and adsorption. Multiple large randomized controlled trials (RCTs) of high-volume hemofiltration (HVHF) for patients with AKI were conducted, but failed to prove the clinical efficacy of HVHF. Blood purification for the removal of mediators through dialysis and filtration using a high cutoff ( $\mathrm{HCO}$ ) membrane hemofilter has not also been established. Furthermore, a HCO membrane hemofilter shares a common problem with HVHF, which is excessive removal of useful substances, such as antimicrobial agents and/or nutrients. Accordingly, continuous hemodiafiltration using cytokine-adsorbing hemofilters (CAH-CHDF) such as polymethylmethacrylate (PMMA) and AN69ST membrane hemofilters has been attracting attention recently. In this review, we report recent findings regarding these old hemofilters with new applications. Although the number of in vitro and in vivo studies conducted to date has been limited, the studies suggest a possibility that these modalities are useful particularly for the treatment of septic shock and septic AKI. CAH-CHDF is expected to be recognized globally as a treatment of septic shock and septic AKI in the near future.
\end{abstract}

Keywords: Cytokine, Adsorption, Sepsis, Renal replacement therapy, Continuous hemodiafiltration, Polymethylmethacrylate, AN69 surface treated, Critical care, Non-renal indication

\section{Background}

Improvement of outcome in acute kidney injury (AKI) by renal replacement therapy (RRT) is an attractive hypothesis. Although AKI is a common clinical condition frequently encountered in the intensive care unit (ICU) [1], a treatment with proven clinical efficacy in AKI has not been established. As a consequence, treatment of AKI mainly involves both treatment of the underlying disease and support for renal function with renal replacement therapy. This is also the case with septic AKI accounting for approximately half of AKI cases experienced in the ICU [1]. The Surviving Sepsis Campaign Guidelines (SSCG) [2], international guidelines for diagnosis and treatment of severe sepsis/septic shock, include

\footnotetext{
* Correspondence: hat@shogo.com

Department of Emergency and Critical Care Medicine, Chiba University, Graduate School of Medicine, 1-8-1 Inohana, Chuo-ku, Chiba city, Chiba 260-8677, Japan
}

(c) 2016 The Author(s). Open Access This article is distributed under the terms of the Creative Commons Attribution 4.0 International License (http://creativecommons.org/licenses/by/4.0/), which permits unrestricted use, distribution, and reproduction in any medium, provided you give appropriate credit to the original author(s) and the source, provide a link to the Creative Commons license, and indicate if changes were made. The Creative Commons Public Domain Dedication waiver (http://creativecommons.org/publicdomain/zero/1.0/) applies to the data made available in this article, unless otherwise stated. little description on the treatment of AKI. Regarding RRT, the SSCG contains nothing but weak recommendations for the choice of intermittent hemodialysis and continuous renal replacement therapy (CRRT). That is, the evidence supporting the hypothesis that blood purification improves outcome of septic AKI remains to be established to date. However, many intensive care physicians and physicians involved in blood purification endorse this hypothesis [3] and have been investigating blood purification techniques that can improve the outcome of septic AKI.

\section{Why cytokine-adsorbing hemofilter?}

Humoral mediators, including cytokines, are well known to be deeply involved in the development of severe sepsis/septic shock [4]. In addition, production of these mediators has been shown to be triggered by pathogen-associated molecular patterns (PAMPs) including lipopolysaccharide (LPS), as well as alarmins (which is produced by injured 
cells and stimulate an immune response [5]) like highmobility group box-1 (HMGB-1) protein, to pattern recognition receptors, such as toll-like receptor [6]. Accordingly, these mediators, PAMPs and alarmins existing in the blood stream are currently considered as target substances for removal by blood purifications for the treatment of septic AKI.

In 1993, Bellomo et al. first reported that various proinflammatory cytokines could be removed by continuous venovenous hemofiltration $(\mathrm{CVVH})$ with dialysis, namely continuous hemodiafiltration (CHDF) [7]. Coincidentally, we focused on the fact that CHDF using polymethylmethacrylate (PMMA) membrane hemofilter (known in the field of chronic maintenance dialysis to efficiently remove $\beta_{2}$-microglobulin $\left(\beta_{2}-\mathrm{MG}\right)$ based on the principle of adsorption [8-10]) in critically ill patients resulted in favorable responses such as rapid improvement of systemic inflammation as well as increase in blood pressure and urine output after initiation of CHDF. Such effects were not obtained when other available membrane hemofilters at that time, such as polysulfone (PS), polyacrylonitrile (PAN), ethylene vinyl alcohol (EVAL), and cellulose triacetate (CTA) were used. We therefore started to investigate removal of mediators by CHDF [11] and reported the clinical efficacy of PMMA-CHDF [12-14].

Other groups have also attempted application of RRT to cytokine modulation for improvement of clinical conditions in sepsis and AKI. Removal of substances by blood purification involves three major principles, namely filtration, dialysis (diffusion), and adsorption. Among the three principles, filtration has been investigated most extensively in the last two decades in the form of a technique increasing filtration volumes (highvolume hemofiltration (HVHF)). Ronco et al. conducted a randomized controlled trial (RCT) that compared therapeutic results of RRT in AKI at three different treatment doses $(20,35$, and $45 \mathrm{~mL} / \mathrm{kg} / \mathrm{h})$ [15]. Results demonstrated that the survival rate was higher in the 35 and $45 \mathrm{~mL} / \mathrm{kg} / \mathrm{h}$ groups than in the $20 \mathrm{~mL} / \mathrm{kg} / \mathrm{h}$ group. Regarding patients with sepsis, the highest survival rate was observed in the $45 \mathrm{~mL} / \mathrm{kg} / \mathrm{h}$ group. The impact of this report was so great that many multicenter RCTs were conducted to confirm the effect of HVHF. However, as large RCTs, such as the ATN [16], RENAL [17], and IVOIRE [18] studies, failed to prove the clinical efficacy of HVHF, HVHF in septic AKI is no longer recommended in a recent consensus statement [19].

Removal of mediators with higher molecular weight (MW) substances based on the principle of dialysis requires enlargement of membrane pore size. Blood purification for removal of mediators by dialysis and filtration using a high cutoff ( $\mathrm{HCO})$ membrane with a larger pore size has been reported by a particular group [20, 21]. While hemodiafiltration using a HCO membrane was reported to exhibit a greater cytokine clearance than that in a conventional membrane and have minimal problematic side effects, no large RCT of this therapy has been conducted and its efficacy has not been established to date. As cytokine removal with a HCO membrane depends on filtration volume and dialysis dose, removal of useful substances, such as antimicrobial agents and nutrients including albumin, considered a problem with HVHF [22], may also be a drawback in this blood purification technique.

As described earlier, the current situation is that the efficacy of HVHF was negated and blood purification with a $\mathrm{HCO}$ membrane has not yet been sufficiently supported by RCTs. Furthermore, HCO membrane shares a common problem with HVHF, which is the excessive removal of useful substances depending on their MW. Accordingly, with mounting expectations for removal of mediators based on the principle of adsorption, cytokine-adsorbing hemofilter $(\mathrm{CAH})$ made of membrane materials with a high adsorption capacity for cytokines is attracting attention from intensive care physicians [3].

Direct hemoperfusion using a polymyxin B endotoxinadsorbing column (PMX-DHP) has been developed in Japan and widely applied for the treatment of septic shock caused by gram negative bacteria for more than 20 years. Although hemodynamic improvement after PMX-DHP treatment has been widely recognized, the efficacy of this modality has not been established yet. EUPHAS study [23], RCT for abdominal sepsis, demonstrated the efficacy of PMX-DHP. However, high mortality rate in the control group and the statistical method has been criticized [24]. Furthermore, another RCT, ABDOMIX study [25] failed to prove the clinical efficacy of PMX-DHP. The mortality rate in the treatment group was higher than that of control group although they were not statistically different [25]. In addition, PMX-DHP is more expensive, and combination use of RRT will be needed in many cases.

\section{Cytokine-adsorbing hemofilter \\ PMMA hemofilter}

The PMMA membrane is a synthetic polymeric membrane prepared by immersing the hydrophobic matrix of PMMA in water to replace with water the organic solvent within the micropore space, utilizing a phenomenon that mixing two methylmethacrylate polymer elements with different tacticity (isotactic PMMA and syndiotactic PMMA) in an organic solvent generates a thermoreversible gel [7]. After marketing authorization of the first PMMA dialyzer in 1977, BK Series ${ }^{\bullet}$ was developed as a newer product lineup with improved water permeability, removal capacity of solutes and excellent biocompatibility, and has been widely used in the field of maintenance dialysis. A PMMA membrane has a symmetric 
microporous structure throughout the entire membrane matrix. Its fractionation characteristic curve is broader than that of other synthetic polymeric membranes, such as PS membrane. It also has an advantage of greater dialysance of middle-MW and high-MW substances (e.g., albumin) compared with the conventionally used cellulose membrane. Furthermore, the PMMA membrane dialyzer was shown to have an excellent ability to remove $\beta_{2}$-MG (MW 11,800 Da), identified as a pathogenic substance of dialysis-related amyloidosis [26]. A subsequent investigation revealed that the $\beta_{2}$-MG level in the dialysate was extremely low when a PMMA dialyzer (BK Series ${ }^{\circ}$ ) was used for hemodialysis and that this phenomenon was due to adsorption of $\beta_{2}$-MG to PMMA membrane [27]. Another subsequent investigation demonstrated that $\beta_{2}$-MG was detectable in the filtrate after the adsorption capacity of the PMMA dialyzer reached saturation level over time [28].

As described earlier, the excellent adsorption characteristics of the PMMA membrane has long been recognized. In 1986, continuous hemofiltration (CHF) was first introduced in the Department of Emergency and Critical Care Medicine, Chiba University Hospital (Chiba, Japan), using a PMMA membrane hemofilter. To ensure both extended filter life and higher removal capacity for solutes, CHF was subsequently replaced by CHDF as the method of choice for CRRT. Through clinical experiences with CHDF using a PMMA membrane hemofilter (PMMA-CHDF) in many critically ill patients, we realized a number of effects that could not be explained as those of RRT alone. These included reduction of abdominal pain and rapid improvement of symptoms of inflammatory response in severe acute pancreatitis, as well as an increased blood pressure and urine volume in patients with acute renal failure soon after initiation of PMMA-CHDF. These facts implied removal of some pathogenic substance(s) related to organ failure by PMMA-CHDF. Therefore, we started an extensive investigation regarding the effects of removal of various humoral mediators, including cytokines, by PMMA-CHDF and the clinical application thereof, which triggered investigations of PMMA-CHDF in other institutions in Japan, by investigators inspired by this idea.

We performed PMMA-CHDF in various conditions and found that the blood levels of various cytokines were lower at the outlet of a hemofilter than at the inlet side. On the other hand, cytokines in the filtrate were scarcely detected, and a positive correlation was observed between blood cytokine levels and the clearance of cytokines by CHDF, which demonstrated that reduction in cytokine levels after hemofilter passage was due to the removal by adsorption to the PMMA membrane hemofilter [29]. Furthermore, a significant decrease of blood cytokine level from the baseline was observed 3 days after initiation of PMMA-CHDF, but not after
CHDF using a hemofilter made of a non-PMMA membrane material [29]. We further investigated and reported that early PMMA-CHDF in addition to early goal-directed therapy (EGDT) in 43 patients with septic shock (mean acute physiology and chronic health evaluation II (APACHE II) score, 29.4; mean sequential organ failure assessment (SOFA) score, 13.7) achieved excellent therapeutic results of recovery rate from shock, $90.7 \%$ and 28-day survival rate, $79.1 \%$ [12]. Matsuda et al. reported a case control study of CRRT in septic AKI involving patients undergoing PMMA-CHDF as the case group and those undergoing CHDF using a PAN membrane hemofilter as the historical control group. They reported a significantly higher survival rate in the PMMACHDF group [30]. Sakamoto et al. comparatively investigated the therapeutic effects of PMMA-CHDF (in 11 patients) and PAN-CHDF (in 7 patients) performed after PMX-DHP. While no significant differences in APACHE II and SOFA scores were observed between the two treatment groups, the survival rate in the PMMA-CHDF group was better than that in the PAN-CHDF group (90.9 vs. $42.9 \%$ ) with significant improvements of the serum plasminogen activator inhibitor-1(PAI-1), protein C, IL-6, and $\mathrm{N}$-arachidonoylethylethanolamine (AEA) [31]. Considering that unlike an AN-69 membrane (described in detail later), PAN membrane used in these studies has no sulfonate group and does not efficiently adsorb humoral mediators such as cytokines, these studies suggest the clinical usefulness of a PMMA hemofilter as a cytokine-adsorbing hemofilter despite limitations in study design and sample size.

A number of in vitro studies reported the cytokine adsorbing characteristics of a PMMA membrane hemofilter. We performed in vitro concentrated perfusion experiments by using ascites with high interleukin (IL)-6 levels to investigate changes in ascites IL-6 level. Results demonstrated that when three different membrane materials (PMMA, CTA, and PS) were compared, the IL-6 removal rate for the PMMA membrane hemofilter was by far greater than that for other membrane hemofilters and IL- 6 was scarcely detectable in the filtrate. When a CTA or a PS membrane hemofilter was used, IL-6 could be removed only at an efficiency lower than that with a PMMA membrane hemofilter and IL- 6 was detected in the filtrate [32]. Furthermore, when direct perfusion of ascites containing high IL-6 levels was performed with these membrane hemofilters, a CTA membrane hemofilter removed only $20 \%$ of IL- 6 , whereas a PMMA membrane filter removed almost $100 \%$ of IL-6 after 3-h perfusion [32]. These results prove that the PMMA membrane adsorbed IL- 6 at a high efficiency. In another in vitro experiment using porcine blood with continuous LPS injection to induce continuous cytokine production, we measured the cytokine clearance of PMMA-CHDF (membrane area, $1.0 \mathrm{~m}^{2}$; blood flow rate: $\mathrm{Q}_{\mathrm{B}}, 80 \mathrm{~mL} / \mathrm{min}$; 
filtration rate: $\mathrm{Q}_{\mathrm{F}}, 300 \mathrm{~mL} / \mathrm{h}$; and dialysate flow rate: $\mathrm{Q}_{\mathrm{D}}, 1000 \mathrm{~mL} / \mathrm{h}$ ) over $24 \mathrm{~h}$. The mean 24-h clearance values for TNF- $\alpha$, IL-6, IL-8, and HMGB-1 were 11.4, $20.9,17.8$, and $11.2 \mathrm{~mL} / \mathrm{min}$, respectively. The cytokineremoving effect of the PMMA membrane hemofilter was maintained during a prolonged CHDF session, though with a slight decrease observed after use for $24 \mathrm{~h}$ (unpublished data). In addition, the cytokine levels in the filtrate were low in this experiment as well, which confirmed that cytokine removal with PMMA membrane was based on the principle of adsorption. Because the production of cytokines continues a few days in severe sepsis/septic shock, it is very important that the ability to adsorb cytokines is kept for long duration.

Tomisawa et al. compared the adsorption characteristics of the PMMA membrane and polyester polymer alloy (PEPA) membrane (both with comparable sieving coefficients) by using chymotrypsinogen (MW 25,000 Da) and albumin (MW 66,000). The PMMA membrane exhibited an adsorption rate approximately $20 \%$ higher than that of the PEPA membrane. In addition, the adsorption rate to the PMMA membrane increased with an increase in filtration rate, while no such change was observed for the PEPA membrane [33, 34]. Based on these findings, Tomisawa et al. considered that the mechanism of adsorption to the PMMA membrane might involve occlusion of protein molecules into pores open in a uniform and symmetric membrane structure. This mechanism may affect water permeability and filter life of PMMA membrane hemofilter. Furthermore, because of the nature of its adsorptive property, PMMA membrane hemofilter is prone to clogging in critically ill patients. Therefore, it is recommended to replace a PMMA hemofilter every $24 \mathrm{~h}$ during the treatment.

\section{AN69 surface-treated hemofilter}

AN69 surface-treated (AN69ST) membrane is a derivative of AN69 (native AN69), originally developed in 1969 as the world's first synthetic polymeric membrane, prepared by surface treatment of polyethyleneimine (PEI). Native AN69 is a copolymer of hydrophobic acrylonitrile and hydrophilic sodium methallylsulfonate and has a symmetric microporous structure. This is also the sole membrane with a hydrogel structure and possesses extremely high hydrophilicity. As AN69 is negatively charged due to sulfonate groups derived from methallylsulfonate monomers, the AN69 membrane adsorbs cytokines via ionic bonding between its sulfonate group and the amino group on the surface of a cytokine molecule. As the AN69 membrane has a hydrogel structure, adsorption to this membrane is considered to take place not only on the membrane surface but also within the bulk layer, thereby exhibiting a high adsorption capacity. In fact, native AN69 membrane is reported to adsorb a greater amount of humoral mediators such as cytokines compared with PS membrane [35].
Gasche et al. performed CVVH using an AN69 membrane hemofilter (AN69-CVVH) in seven patients and reported removal of factor $\mathrm{D}$ (activating complement) by adsorption [36]. De Vriese et al. performed AN69-CVVH in 15 patients with septic AKI and reported a rapid decrease in blood cytokine levels and improvement in cardiac output, pulmonary artery wedge pressure, and systemic vascular resistance [37]. However, cytokine levels, once reduced, subsequently increased again during $\mathrm{CVVH}$ and the AN69 hemofilter had to be replaced once every $3 \mathrm{~h}$. Kellum et al. demonstrated that AN69-CVVH in a murine sepsis model induced by cecal ligation and puncture suppressed an increase in blood IL-6 level [38]. When Rogiers et al. performed CVVH using either a PS or an AN69 membrane hemofilter in dogs injected with endotoxin, significantly higher cardiac output, stroke volume, and left ventricular stroke work index were observed in the AN69 group [35].

Native AN69 membrane negatively charged even on the membrane surface is known to generate bradykinin in contact with blood. In particular, when a patient takes angiotensin-converting enzyme (ACE) inhibitors, kininase II that inactivates bradykinin is inhibited and causes serious hypotension, which has been a serious disadvantage of AN69 membrane. Partial coating of the surface of the AN69 membrane with a biocompatible cation PEI reduced the zeta potential on the contact surface between the membrane and blood, thereby reducing bradykinin production greatly, although not all patients were free from this adverse event [39].

The AN69ST membrane is known to have excellent anti-thrombogenicity as well. AN69/AN69ST membranes have a hydrogel structure and are therefore highly hydrophilic. Furthermore, the surface of the AN69ST membrane can be coated with heparin by priming with saline-containing heparin. As a consequence, the anti-thrombogenicity of the AN69ST membrane exceeds that of the native AN69 membrane and anticoagulant-free hemodialysis using AN69ST membrane has been reported $[40,41]$. On the other hand, as the sulfonyl groups on the AN69 membrane adsorb nafamostate mesilate, this anticoagulant is not compatible enough with the AN69/ AN69ST membrane [42]. Appropriate priming is most important and unfractionated heparin or low molecular weight heparin is recommended if possible. If nafamostate mesilate is the only anticoagulant to use e.g., trauma patient, it should be infused from not only pre-hemofilter but also post-hemofilter.

Reports of basic research on the cytokine-adsorbing capacity of the AN69ST membrane and clinical studies of this membrane are limited. Yumoto et al. compared four different membrane hemofilter, (AN69ST, PMMA, $\mathrm{HCO}$ polyarylethersulfone; PAES, and PS) concerning the capacity to remove HMBG1 in vitro. AN69ST had the highest efficiency of HMBG1 removal, followed by the 
PMMA membrane. PAES and PS membrane removed little amount of HMGB-1 [43]. In a clinical study, Shiga et al., conducted a single-arm multicenter study involving CHDF using a AN69ST membrane hemofilter (SepXiris ${ }^{\circ}$ ) in 34 patients with severe sepsis and septic shock associated with hyperlactatemia (blood lactate $>36 \mathrm{mg} / \mathrm{dL}$ ). Even in very severe critically ill patients (mean APACHE II score, $32.7 \pm 9.8$ ), the 28 -day survival rate was as high as 73.5 \% (Fig. 1) [44]. Based on these results, CHDF using an AN69ST hemofilter in severe sepsis was formally approved by the National Health Insurance System in Japan since July 2014, as a non-renal indication.

\section{Modified AN69ST (oXiris ${ }^{\circledast}$ )}

The oXiris ${ }^{\circ}$ is a hemofilter using the AN69 membrane with PEI surface coating and immobilized heparin. Compared with the AN69ST membrane, the oXiris ${ }^{\circ}$ has 3 times greater amount of PEI surface coating (in the second layer) and 10 times greater amount of pre-immobilized heparin (in the third layer). As a consequence, oXiris ${ }^{\bullet}$ has excellent anti-thrombogenicity and is capable of adsorbing endotoxin (supposed to be negatively charged) to cationic PEI in the second layer [45]. Bottom bulk layer of the oXiris ${ }^{\circ}$ membrane remains negatively charged and thereby retains its ability to adsorb cytokines. That is, the oXiris ${ }^{\oplus}$ membrane is intended to adsorb both endotoxin and cytokines.

In vitro experiments by Rimmele et al. that compared the ability to adsorb cytokines (TNF- $\alpha$, IL-18, IL-6, and IL-1Ra) among three different membranes (PS, AN69, and oXiris ${ }^{\circ}$ ) demonstrated that the AN69 and oXiris ${ }^{\circ}$ membranes adsorb cytokines substantially, while the PS membrane adsorbs little cytokines. Furthermore, the oXiris ${ }^{\circ}$ adsorbed more cytokines and endotoxin than the AN69 membrane [45]. When 6-h HVHF was performed in a porcine model of sepsis by using either an AN69 or oXiris ${ }^{\circledR}$ membrane hemofilter, the blood endotoxin level was significantly lower in the oXiris ${ }^{\circ}$ group. In addition, the values of crystalloid infusion volume, colloid infusion volume, degree of lactic acidosis, and pulmonary arterial pressure were significantly lower in the oXiris ${ }^{\circ}$ group [45].

We measured cytokine clearance of oXiris ${ }^{\circ}$-CHDF (membrane area, $1.5 \mathrm{~m}^{2}$; $\mathrm{Q}_{\mathrm{B}}, 80 \mathrm{~mL} / \mathrm{min}$; $\mathrm{Q}_{\mathrm{F}}, 300 \mathrm{~mL} / \mathrm{h}$; $\mathrm{Q}_{\mathrm{D}}$, $1000 \mathrm{~mL} / \mathrm{h}$ ) over $24 \mathrm{~h}$, using porcine blood with LPS continuous injection to induce continuous cytokine production. The mean 24-h clearance values for TNF- $\alpha$, IL-6, IL-8, and HMGB-1 were $15.2,18.3,25.3$, and $23.5 \mathrm{~mL} / \mathrm{min}$, respectively. The sieving coefficients for these cytokines were all less than 0.02 , and removal by filtration was negligible [46].

While the clinical effects of the oXiris ${ }^{\circ}$ membrane hemofilter have scarcely been reported, Shum et al. performed oXiris ${ }^{\circ} \mathrm{CVVH}$ in six patients with septic AKI and compared with 24 severity-matched historical controls undergoing PS-CVVH. Results demonstrated that the SOFA score after 48-h CVVH was reduced from the value at ICU admission by $38 \%$ in the oXiris group, while an increase of $3 \%$ was observed in the control group. No significant difference was observed in ICU and in-hospital mortality between the two groups [47].

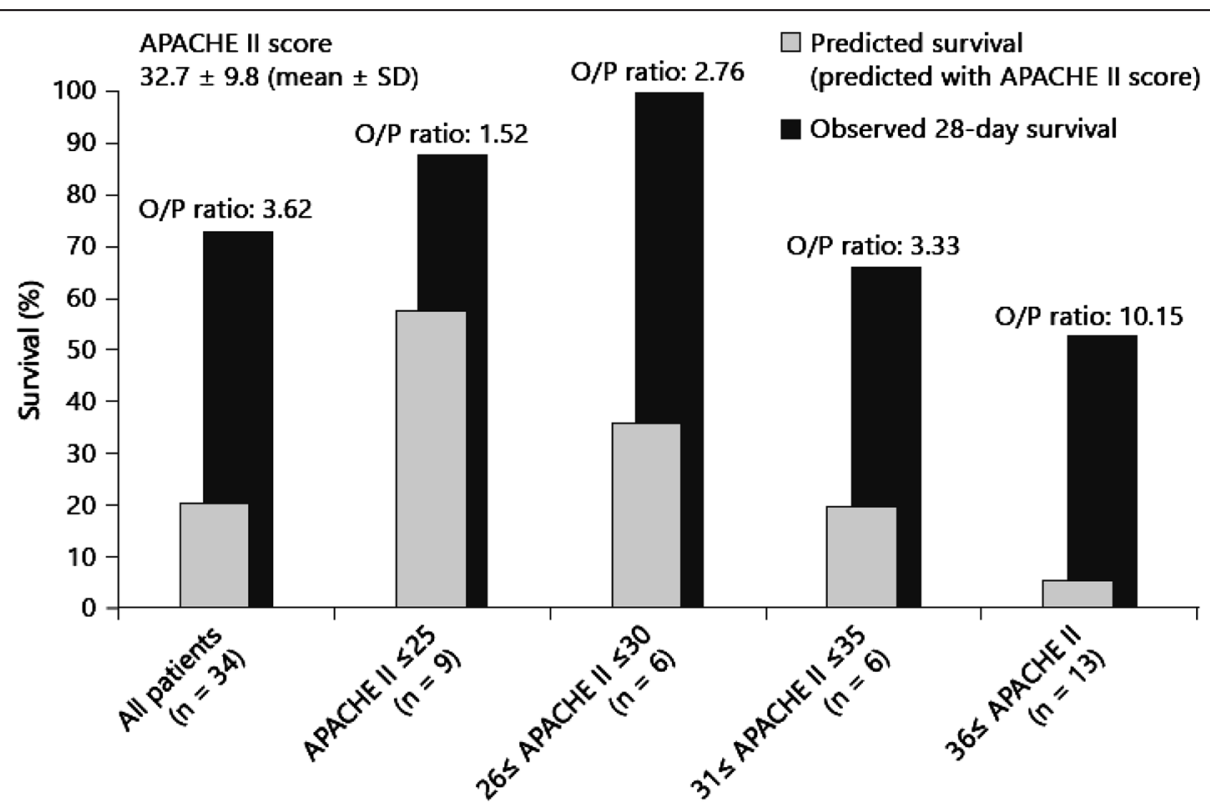

Fig. 1 Comparison of predicted survival, observed 28-day survival and the observed/predicted survival ratio among the subgroups stratified according to the APACHE II score. O/P ratio: observed survival rate divided by predicted survival rate. Image originally published in Shiga $\mathrm{H}$, Hirasawa H, Nishida O, Oda S, Nakamura M, Mashiko K, Matsuda K, Kitamura N, Kikuchi Y, Fuke N, Continuous Hemodiafiltration with a Cytokine-Adsorbing Hemofilter in Patients with Septic Shock: A Preliminary Report. Blood Purif 2014;38:211-218. Image copyright Karger AG. All rights reserved 
In Switzerland, an RCT that compares the efficacy of oXiris ${ }^{\circ}-\mathrm{CVVH}$ and PMX-DHP in patients with septic shock is currently in progress (ENDoX study). Furthermore, Honore et al. state in their review article that they are planning an RCT to compare four different membrane hemofilters (AN69, AN69ST, oXiris ${ }^{\circ}$, and PAES) in septic shock with AKI [48].

\section{Future perspectives of CAH-CHDF}

The concept of $\mathrm{CAH}$ and treatment based on this concept has been investigated mainly in Japan by using a PMMA hemofilter. Accordingly, the Japanese Guidelines for the management of sepsis [49] include a weak recommendation for CHDF for mediator removal, with a comment that there is a possibility to improve hemodynamics, though without sufficient evidence supporting improving outcome. While potentials of the AN69ST and oXiris ${ }^{\circ}$ hemofilters with excellent adsorption capacity for cytokines have been recently attracting the attention of ICU physicians in Europe and the USA, evidence for these modalities are obviously lacking. Many clinical studies, including large-scale RCTs, are expected to be planned, and some clinical trials are currently ongoing.

What is necessary for establishing the clinical efficacy of CAH-CHDF for the treatment of severe sepsis and septic AKI in the future, in other words, what is necessary for obtaining positive results in clinical trials to be planned in the future? Adsorption is more efficient at higher concentrations of the target substance in the blood. Consequently, the effects of mediator removal using $\mathrm{CAH}$ may be demonstrated more clearly in patients treated at higher concentration of mediators such as cytokines. Since we introduced a rapid IL- 6 assay system into the clinical laboratory of Chiba University Hospital in April 2000, we have measured blood IL- 6 level in various clinical conditions and reported that blood IL-6 levels reflect the severity of systemic inflammatory response syndrome (SIRS) and sepsis and increased blood IL-6 level is closely associated with severity of organ dysfunction [50]. Therefore, we consider that selective application of CAH-CHDF to critically ill patients with hypercytokinemia based on the measurement of blood IL-6 level is crucial to obtain better therapeutic effect.

In the study of Nakada et al. that investigated the usefulness of PMMA-CHDF for septic shock, the subjects were very critically ill patients as indicated by the following clinical parameters: mean blood IL-6 level, 132,300 pg/mL (median, 23,480 pg/mL); mean APACHE II score, 29.4; mean SOFA score, 13.7; and mean blood lactate level, $72.2 \mathrm{mg} / \mathrm{dL}$ [12]. The single-arm study of AN69ST-CHDF by Shiga et al. exclusively included subjects of severe sepsis/septic shock with a blood lactate level more than $36 \mathrm{mg} / \mathrm{dL}(4 \mathrm{mmol} / \mathrm{L})$. Their clinical parameters indicated the following severe clinical conditions: mean blood IL-6 level, 44,800 pg/mL; mean APACHE II score, 32.7; and mean blood lactate level, $69.0 \mathrm{mg} / \mathrm{dL}$. The subjects of the oXiris ${ }^{\circ}-\mathrm{CVVH}$ study by Shum et al. had a median APACHE II score of 36 (Table 1) [47]. Consequently, the selection of subjects based on actual measurements of humoral mediators such as IL-6 may be the key in clinical studies of CAH to be planned in the future. IL- 6 is relatively stable in blood, and an automated assay system that can rapidly measure blood IL-6 level in approximately $30 \mathrm{~min}$ is commercially available. We currently utilize a rapid assay of IL-6 (Roche Diagnostics GmbH, Mannheim, Germany) for determination of a treatment strategy for severe sepsis and septic shock and for evaluation of treatment effects. To measure blood IL-6 levels enable to decide implementation of CAH-CHDF earlier before AKI become obvious. In our institute, the cutoff value to initiate $\mathrm{CAH}-\mathrm{CHDF}$ is $10,000 \mathrm{pg} / \mathrm{mL}$ because IL- 6 blood level in septic shock usually exceeds $10,000 \mathrm{pg} / \mathrm{mL}$ and is

Table 1 Backgrounds of the patients in the previous reports

\begin{tabular}{|c|c|c|c|c|c|}
\hline Author & Nakada [12] & Sakamoto [31] & Matsuda [30] & Shiga [44] & Shum [47] \\
\hline Publication year & 2008 & 2008 & 2011 & 2012 & 2013 \\
\hline Hemofilter & PMMA & PMMA & PMMA & AN69ST & oXiris ${ }^{\circledast}$ \\
\hline Number of patients & 43 & 11 & 30 & 34 & 6 \\
\hline Age & $63.5 \pm 13.3$ & $63.2 \pm 10.8$ & $63.9 \pm 12.3$ & $67.1 \pm 12.1$ & $61(51-67)$ \\
\hline APACHE I| score & $29.4 \pm 8.4$ & $24.8 \pm 8.6$ & $29.0 \pm 6.7$ & $32.7 \pm 9.8$ & $36(28-41)$ \\
\hline SOFA score & $13.7 \pm 3.7$ & $9.7 \pm 4.1$ & $13.0 \pm 3.7$ & NA & NA \\
\hline Lactate, mg/dL & $72.2 \pm 40.4$ & NA & NA & $69.0 \pm 49.4$ & NA \\
\hline Interleukin-6, pg/mL & $132300 \pm 243700$ & $7893.8 \pm 10238.4$ & NA & $44800 \pm 77700$ & NA \\
\hline Predicted survival rate ${ }^{a}, \%$ & 32.8 & NA & 35.6 & 20.3 & $15(8-36)$ \\
\hline 28-day survival rate, \% & 79.1 & 90.9 & 83.3 & 73.5 & $66.7^{\mathrm{b}}$ \\
\hline
\end{tabular}

Data are presented as mean \pm SD or median (interquartile range)

${ }^{a}$ Survival rate calculated by APACHE II score

${ }^{\text {b}}$ Survival rate at ICU discharge

$N A$ not available, APACHE acute physiology and chronic health evaluation, SOFA sequential organ failure assessment 
significantly higher than those in severe sepsis/sepsis/SIRS [50]. However, some cases with high SOFA score whose IL-6 blood level is between 1000 and 10,000 pg/mL indicate poor outcomes [50] so that we consider to implement $\mathrm{CAH}-\mathrm{CHDF}$ in also such cases.

In brief, we believe that the patient selection for CAHCHDF based on actual measurements of mediators such as IL-6 will be the key to successful clinical application of $\mathrm{CAH}$. If this is impossible, exclusive selection of most critically ill patients using clinical parameters such as the APACHE II and SOFA score, or blood lactate level would be favorable.

\section{Conclusions}

It is interesting that classical hemofilters based on the PMMA (approved in 1977) and AN69 membranes (developed in 1969) have played new roles in cytokine removal by adsorption and control of hypercytokinemia and are thereby attracting attention again in the twentyfirst century. Today is the scholar of yesterday ("on-ko chishin" in Japanese). Some of in vitro and in vivo studies suggest a possibility that these old modalities with new applications may be particularly useful in the treatment of septic shock and septic AKI. It is important to understand the characteristics of individual hemofilters and to select a patient to whom CAHs are clinically beneficial based on the appropriate method. We expect that CAH-CHDF will be recognized globally as an option for the treatment of septic shock and septic AKI in the near future.

\begin{abstract}
Abbreviations
AKI, acute kidney injury; AN69ST, AN69 surface treated; ATN, Acute Renal Failure Trial Network; APACHE II, acute physiology and chronic health evaluation $I$; $\beta_{2}-M G$, $\beta_{2}$-microglobulin; $C A H$, cytokine adsorbing hemofilter; CHDF, continuous hemodiafiltraion; CHF, continuous hemofiltration; CRRT, continuous renal replacement therapy; $\mathrm{CWH}$, continuous venovenous hemofiltration; EUPHAS, Early Use of Polymyxin B Hemoperfusion in Abdominal Sepsis; HCO, high cutoff; HMGB-1, high-mobility group box-1; HVHF, high-volume hemofiltration; ICU, intensive care unit; IL, interleukin; IVOIRE, High-volume versus standard-volume haemofiltration for septic shock patients with acute kidney injury; LPS, lipopolysaccharide; PAES, polyarylethersulfone; PAMPs, pathogen-associated molecular patterns; PAN, polyacrylonitrile; PEPA, polyester polymer alloy; PMMA, polymethylmethacrylate; PMX-DHP, polymyxin B immobilized fiber column direct hemoperfusion; PS, polysulfone; RCT, randomized controlled trial; RENAL, Randomized Evaluation of Normal versus Augmented Level; RRT, renal replacement therapy; SIRS, systemic inflammatory response syndrome; SOFA, sequential organ failure assessment; SSCG, Surviving Sepsis Campaign Guidelines
\end{abstract}

\section{Funding}

The source funding of this review is the Department of Emergency and Critical Care Medicine, Chiba University, Graduate School of Medicine.

\section{Authors' contributions}

$\mathrm{NH}$ planned this review, and drafted the manuscript. SO supervised and made suggestions for the drafting of the manuscript. Both authors read and approved the final manuscript.

\section{Competing interests}

The authors declare that they have no competing interests.
Received: 16 December 2015 Accepted: 13 May 2016

Published online: 18 July 2016

\section{References}

1. Uchino S, Kellum JA, Bellomo R, Doig GS, Morimatsu H, Morgera S, et al. Acute renal failure in critically ill patients: a multinational, multicenter study. JAMA. 2005;294:813-8.

2. Dellinger RP, Levy MM, Rhodes A, Annane D, Gerlach H, Opal SM, et al. Surviving sepsis campaign: international guidelines for management of severe sepsis and septic shock: 2012. Crit Care Med. 2013;41:580-637.

3. Legrand M, Darmon M, Joannidis M, Payen D. Management of renal replacement therapy in ICU patients: an international survey. Intensive Care Med. 2013;39:101-8.

4. Russell JA. Management of sepsis. N Engl J Med. 2006;355:1699-713.

5. Chan JK, Roth J, Oppenheim JJ, Tracey KJ, Vogl T, Feldmann M, et al. Alarmins: awaiting a clinical response. J Clin Invest. 2012;122:2711-9.

6. Annane D, Bellissant E, Cavaillon JM. Septic shock. Lancet. 2005;365:63-78.

7. Bellomo R, Tipping P, Boyce N. Continuous veno-venous hemofiltration with dialysis removes cytokines from the circulation of septic patients. Crit Care Med. 1993;21:522-6.

8. Wada S, Sugaya H. Hollow fiber type membranes for artificial kidney. -Polymethylmethacrylate (PMMA) membranes, Polysulfone membranesMembrane. 2004;29:131-6.

9. Gejyo F, Yamada T, Odani S, Nakagawa Y, Arakawa M, Kunitomo T, et al. A new form of amyloid protein associated with chronic hemodialysis was identified as beta 2-microglobulin. Biochem Biophys Res Commun. 1985;129:701-6.

10. Takesawa S, Ohashi H, Hidai H, Sakai K. Effects of membrane structure on removal of low molecular weight proteins. Artif Organs. 1987;11:495-7.

11. Hirasawa H, Sugai T, Ohtake Y, Oda S, Matsuda K, Kitamura N. Blood purification for prevention and treatment of multiple organ failure. World J Surg. 1996;20:482-6.

12. Nakada TA, Oda S, Matsuda K, Sadahiro T, Nakamura M, Abe R, et al. Continuous hemodiafiltration with PMMA hemofilter in the treatment of patients with septic shock. Mol Med. 2008;14:257-63.

13. Nakamura M, Oda S, Sadahiro T, Hirayama Y, Watanabe E, Tateishi Y, et al. Treatment of severe sepsis and septic shock by CHDF using a PMMA membrane hemofilter as a cytokine modulator. Contrib Nephrol. 2010;166:73-82.

14. Hirasawa H, Oda S, Matsuda K. Continuous hemodiafiltration with cytokineadsorbing hemofilter in the treatment of severe sepsis and septic shock. Contrib Nephrol. 2007;156:365-70.

15. Ronco C, Bellomo R, Homel P, Brendolan A, Dan M, Piccinni P, et al. Effects of different doses in continuous veno-venous haemofiltration on outcomes of acute renal failure: a prospective randomised trial. Lancet. 2000;356:26-30.

16. Palevsky PM, Zhang JH, O'Connor TZ, Chertow GM, Crowley ST, Choudhury D, et al. Intensity of renal support in critically ill patients with acute kidney injury. N Engl J Med. 2008;359:7-20.

17. Bellomo R, Cass A, Cole L, Finfer S, Gallagher M, Lo S, et al. Intensity of continuous renal-replacement therapy in critically ill patients. N Engl J Med. 2009;361:1627-38.

18. Joannes-Boyau O, Honore PM, Perez P, Bagshaw SM, Grand H, Canivet JL, et al. High-volume versus standard-volume haemofiltration for septic shock patients with acute kidney injury (IVOIRE study): a multicentre randomized controlled trial. Intensive Care Med. 2013;39:1535-46.

19. Brochard L, Abroug F, Brenner M, Broccard AF, Danner RL, Ferrer M, et al. An official ATS/ERS/ESICM/SCCM/SRLF statement: prevention and management of acute renal failure in the ICU patient: an international consensus conference in intensive care medicine. Am J Respir Crit Care Med. 2010;181:1128-55.

20. Morgera S, Haase M, Kuss T, Vargas-Hein O, Zuckermann-Becker H, Melzer C, et al. Pilot study on the effects of high cutoff hemofiltration on the need for norepinephrine in septic patients with acute renal failure. Crit Care Med. 2006;34:2099-104.

21. Haase M, Bellomo R, Baldwin I, Haase-Fielitz A, Fealy N, Davenport P, et al. Hemodialysis membrane with a high-molecular-weight cutoff and cytokine levels in sepsis complicated by acute renal failure: a phase 1 randomized trial. Am J Kidney Dis. 2007;50:296-304.

22. Schiffl $\mathrm{H}$. The dark side of high-intensity renal replacement therapy of acute kidney injury in critically ill patients. Int Urol Nephrol. 2010;42:435-40. 
23. Cruz DN, Antonelli M, Fumagalli R, Foltran F, Brienza N, Donati A, et al. Early use of polymyxin B hemoperfusion in abdominal septic shock: the EUPHAS randomized controlled trial. JAMA. 2009;301:2445-52.

24. Vincent JL. Polymyxin $B$, hemoperfusion and mortality in abdominal septic shock. JAMA. 2009;302:1968-70.

25. Payen DM, Guilhot J, Launey Y, Lukaszewicz AC, Kaaki M, Veber B, et al. Early use of polymyxin B hemoperfusion in patients with septic shock due to peritonitis: a multicenter randomized control trial. Intensive Care Med. 2015;41:975-84.

26. Ono T, Iwamoto N, Kataoka H, Yamada S, Sakai Y, Kunitomo T. Clinical significance of a dialysis membrane that can remove beta 2-microglobulin (beta 2m). ASAIO Trans. 1988;34:342-5.

27. Yamada S, Kataoka H, Kobayashi H, Ono T, Minakuchi J, Kawano Y. Identification of an erythropoietic inhibitor from the dialysate collected in the hemodialysis with PMMA membrane (BK-F). Contrib Nephrol. 1999;125:159-72.

28. Ishikawa I, Chikazawa Y, Sato K, Nakagawa M, Imamura H, Hayama S, et al. Proteomic analysis of serum, outflow dialysate and adsorbed protein onto dialysis membranes (polysulfone and pmma) during hemodialysis treatment using SELDI-TOF-MS. Am J Nephrol. 2006;26:372-80.

29. Matsuda K, Hirasawa H, Oda S, Shiga H, Nakanishi K. Current topics on cytokine removal technologies. Ther Apher. 2001;5:306-14.

30. Matsuda K, Moriguchi T, Harii N, Yanagisawa M, Harada D, Sugawara H. Comparison of efficacy between continuous hemodiafiltration with a PMMA high-performance membrane dialyzer and a PAN membrane hemofilter in the treatment of septic shock patients with acute renal failure. Contrib Nephrol. 2011;173:182-90.

31. Sakamoto Y, Mashiko K, Obata T, Matsumoto H, Hara Y, Kutsukata N, et al. Effectiveness of continuous hemodiafiltration using a polymethylmethacrylate membrane hemofilter after polymyxin Bimmobilized fiber column therapy of septic shock. ASAIO J. 2008:54:129-32.

32. Hirayama Y, Oda S, Wakabayashi K, Sadahiro T, Nakamura M, Watanabe E, et al. Comparison of interleukin- 6 removal properties among hemofilters consisting of varying membrane materials and surface areas: an in vitro study. Blood Purif. 2011;31:18-25.

33. Tomisawa N, Yamashita AC. Amount of adsorbed albumin loss by dialysis membranes with protein adsorption. J Artif Organs. 2009;12:194-9.

34. Yamashita AC, Tomiasawa N. Membrane materials for blood purification in critical care. Contrib Nephrol. 2010;166:112-8.

35. Rogiers $\mathrm{P}$, Zhang $\mathrm{H}$, Pauwels D, Vincent JL. Comparison of polyacrylonitrile (AN69) and polysulphone membrane during hemofiltration in canine endotoxic shock. Crit Care Med. 2003;31:1219-25.

36. Gasche Y, Pascual M, Suter PM, Favre H, Chevrolet JC, Schifferli JA. Complement depletion during haemofiltration with polyacrilonitrile membranes. Nephrol Dial Transplant. 1996;11:117-9.

37. De Vriese AS, Colardyn FA, Philippe JJ, Vanholder RC, De Sutter JH, Lameire $\mathrm{NH}$. Cytokine removal during continuous hemofiltration in septic patients. J Am Soc Nephrol. 1999;10:846-53.

38. Kellum JA, Dishart MK. Effect of hemofiltration filter adsorption on circulating IL-6 levels in septic rats. Crit Care. 2002;6:429-33.

39. Roux VD, Plaisance M. Abdominal manifestations associated with use of a surface-treated AN69 membrane and ACEl during haemodialysis. Nephrol Dial Transplant. 2007;22(6):1792-3.

40. Chanard J, Lavaud S, Maheut H, Kazes I, Vitry F, Rieu P. The clinical evaluation of low-dose heparin in haemodialysis: a prospective study using the heparincoated AN69 ST membrane. Nephrol Dial Transplant. 2008;23:2003-9.

41. Guery B, Alberti C, Servais A, Harrami E, Bererhi L, Zins B, et al. Hemodialysis without systemic anticoagulation: a prospective randomized trial to evaluate 3 strategies in patients at risk of bleeding. PLoS ONE. 2014;9:e97187.

42. Inagaki O, Nishian Y, Iwaki R, Nakagawa K, Takamitsu Y, Fujita Y. Adsorption of nafamostat mesilate by hemodialysis membranes. Artif Organs. 1992;16:553-8.

43. Yumoto M, Nishida O, Moriyama K, Shimomura Y, Nakamura T, Kuriyama N, et al. In vitro evaluation of high mobility group box 1 protein removal with various membranes for continuous hemofiltration. Ther Apher Dial. 2011;15:385-93.

44. Shiga H, Hirasawa H, Nishida O, Oda S, Nakamura M, Mashiko K, et al. Continuous hemodiafiltration with a cytokine-adsorbing hemofilter in patients with septic shock: a preliminary report. Blood Purif. 2014;38:211-8.

45. Rimmele T, Assadi A, Cattenoz M, Desebbe O, Lambert C, Boselli $E$, et al. High-volume haemofiltration with a new haemofiltration membrane having enhanced adsorption properties in septic pigs. Nephrol Dial Transplant. 2009:24:421-7

46. Hirayama Y, Oda S, Sadahiro T, Nakamura M, Watanabe E, Tateishi Y. Removal properties of inflammatory mediators, including HMGB-1, by newly developed heparin grafted AN69ST membrane hemofilter(oXiris ${ }^{\circledast}$ ). J Jpn Soc Blood Purif Crit Care. 2011;2:187-93.

47. Shum HP, Chan KC, Kwan MC, Yan WW. Application of endotoxin and cytokine adsorption haemofilter in septic acute kidney injury due to gram-negative bacterial infection. Hong Kong Med J. 2013;19:491-7.

48. Honore PM, Jacobs R, Joannes-Boyau O, De Regt J, De Waele E, van Gorp V, et al. Newly designed CRRT membranes for sepsis and SIRS — a pragmatic approach for bedside intensivists summarizing the more recent advances: a systematic structured review. ASAIO J. 2013;59:99-106.

49. Oda S, Aibiki M, Ikeda T, Imaizumi H, Endo S, Ochiai R, et al. The Japanese guidelines for the management of sepsis. J Intensive Care. 2014;2:55.

50. Oda S, Hirasawa H, Shiga H, Nakanishi K, Matsuda K, Nakamua M. Sequential measurement of IL-6 blood levels in patients with systemic inflammatory response syndrome (SIRS)/sepsis. Cytokine. 2005;29:169-75.

\section{Submit your next manuscript to BioMed Central and we will help you at every step:}

- We accept pre-submission inquiries

- Our selector tool helps you to find the most relevant journal

- We provide round the clock customer support

- Convenient online submission

- Thorough peer review

- Inclusion in PubMed and all major indexing services

- Maximum visibility for your research

Submit your manuscript at www.biomedcentral.com/submit
Ciomed Central 